\title{
MILK Symposium review: Milk consumption is associated with better height and weight in rural Nepali children over 60 months of age and better head circumference in children 24 to 60 months of age*
}

\author{
Laurie C. Miller, ${ }^{1} \dagger$ ๑ Sumanta Neupane, ${ }^{2}$ ๑ Neena Joshi, ${ }^{3}$ and Mahendra Lohani ${ }^{4}$ \\ ${ }^{1}$ Department of Pediatrics, Friedman School of Nutrition Science and Policy, Eliot-Pearson Department of Child Study and Human Development, \\ Tufts University, Boston, MA 02111 \\ ${ }^{2}$ International Food Policy Research Institute, Dev Prakash Shastri Marg, Pusa, Delhi 110012, India \\ ${ }^{3}$ Heifer Nepal, Sadobato Road, Lalitpur 44700, Nepal \\ ${ }^{4}$ Heifer International, Little Rock, AR 72202
}

\begin{abstract}
Child undernutrition afflicts $>150$ million children worldwide, contributing to poor child growth, increased risk of infections, and loss of developmental potential. Animal-source foods (ASF) can ameliorate these problems by providing high-quality, high-density, and bioavailable protein and micronutrients. However, many children in developing countries lack ASF in their diet, although generally milk is the ASF most often consumed. Nevertheless, the relation of ASF - and that of specific ASF - to child growth in these contexts has been difficult to define, as has the association between diet and child and household factors in influencing growth outcomes. To better understand these relationships, we evaluated child growth by age groups (6-23 mo, 24-60 mo, and $>60 \mathrm{mo}$ ) in relation to ASF consumption in rural Nepal. We used an observational study design that leveraged a data set generated through a 3-yr longitudinal controlled impact evaluation of a communitydevelopment intervention. Child anthropometry and 24-h diet recall were obtained at 5 household visits. At baseline, children were generally undernourished: $47 \%$ were stunted, $46 \%$ underweight, $17 \%$ wasted, and $24 \%$ microcephalic. Patterns of undernutrition varied with age but improved somewhat over time. Over the 3 -yr period of study (9,283 observations), ASF were consumed infrequently: milk in $28 \%$ of assessments, meat in $27 \%$, and eggs in $15 \%$. Consumption patterns differed by age group, with younger children (6-23 mo)
\end{abstract}

Received January 30, 2020.

Accepted May 7, 2020.

*Presented as part of the MILK Symposium: Improving Milk Production, Quality, and Safety in Developing Countries at the ADSA Annual Meeting, Cincinnati, Ohio, June 2019.

†Corresponding author: laurie.miller@tufts.edu consuming more milk and less meat than children 24 to 60 or $>60$ mo. Consumption of even a single ASF at any of the 5 surveys was associated with greater growth in bivariate analysis. After adjustment for household (group assignment, survey round and its interaction, wealth, income, livestock and land ownership, maternal education) and child factors (age, sex, baseline anthropometry), mixed-effect linear regression analysis showed that milk consumption related to higher height for age and weight for age z-scores for children $>60$ mo of age and to higher head circumference z-score for children age 24 to 60 mo. For children $>60$ mo, egg consumption also related to higher weight z-scores. Household and child factors also influenced these outcomes. Of the ASF, milk had the strongest and most consistent relationship to child growth. Better measures of diet intake could reveal stronger associations between diet consumption patterns and child growth. Regardless, milk may be a key ASF to target for growth promotion among undernourished rural Nepali children.

Key words: animal-source foods (ASF), milk, child, Nepal, growth

\section{INTRODUCTION}

Undernutrition afflicts many millions of children globally (UNICEF, 2018). Worldwide, more than 155 million children are stunted, and more than 52 million are wasted. Child growth is of particular interest in population studies because it reflects multiple environmental factors and may serve as a proxy measure for child well-being. Especially in resource-poor settings, family characteristics - such as sociodemographic status, educational achievements, household hygiene, parenting practices, and child diet adequacy-usually overshadow the influence of genetics in determining growth (Prado and Dewey, 2014; Johnson et al., 2016; Persson, 2017). Particular attention has been given 
to child diet, as it is perhaps one of the more readily measurable, as well as potentially modifiable, factors influencing child growth outcomes.

Multiple studies have focused on the relationship of animal-source foods (ASF) to child growth (Allen, 1993; Marquis et al., 1997; Neumann et al., 2002, 2003, 2007; Grillenberger et al., 2006; Allen and Dror, 2011; Bolton, 2019; Pimpin et al., 2019; Shapiro et al., 2019). In a comprehensive analysis of demographic and health survey data from 46 low- and middle-income countries (112,553 children 6-23 mo of age), strong associations between the consumption of ASF and child growth were found (Headey et al., 2017). Nutrition-related mechanisms that might support growth include the readily bioavailable high-quality proteins and micronutrients (iron, zinc, iodine, essential fatty acids, $\mathrm{B}_{12}$, and other nutrients) contained in ASF (reviewed in Dror and Allen, 2011). The concentrated form of the nutrients found in ASF also offers an important advantage to small children with limited gastric capacity. However, many studies (both observational and randomized controlled trials using food supplements) examining the relationship between ASF consumption and growth have had mixed or inconclusive results. Several recent systematic reviews and meta-analyses (Eaton et al., 2019; Pimpin et al., 2019; Shapiro et al., 2019) have highlighted the difficulties in this area. Small effect sizes, inconsistent results, marked heterogeneity in study designs, and sample characteristics have contributed to reduced quality of evidence linking ASF consumption to better growth (Allen and Dror, 2011; Eaton et al., 2019; Pimpin et al., 2019).

These and other analyses have highlighted important research gaps (Headey et al., 2017; Eaton et al., 2019; Pimpin et al., 2019). For example, the need for adequate duration of follow-up has been cited (Miller et al., 2017a). Child growth is a complex and dynamic process; changes in growth related to modifications in diet are not instantaneous, but become manifest over months or, more likely, years. Although many studies focus on children $<24$ mo of age, improvements in growth may occur even long after the "1,000 day" period (Eaton et al., 2019). Additionally, critical periods for consumption of key nutrients have not been fully defined; epigenetic changes related to diet in early life (along with other factors) may have long-term consequences for child growth, health, and development (Jang and Serra, 2014; Bhutta et al., 2017; Closa-Monasterolo et al., 2017). Yet, with several notable exceptions (Neumann et al., 2003; Headey et al., 2017, Bolton, 2019), food supplement intervention studies seldom examine the relative benefits of different ASF (e.g., milk vs. meat vs. eggs) in the same setting. The importance of study- ing whole foods (vs. an isolated food component such as a vitamin or mineral) has also been cited (Pimpin et al., 2019), as nonprotein components of ASF may also influence growth outcomes. The necessity to account for relevant household and child factors in assessing growth outcomes has also been emphasized.

We have previously reported that a previous community-development intervention in rural Nepal was associated with increased ASF consumption and independently with improved growth among young children (Miller et al., 2014; Darrouzet-Nardi et al., 2016; Miller et al., 2017). These changes were seen despite the fact that the community-development activities did not include any specific nutrition education or special focus on child diet or health.

To explore these relationships further, we conducted a new study in a different region of Nepal (Banke district), and used a different intervention. The new intervention included a nutrition education component that focused on children and women of child-bearing age, and encouraged diet diversity and ASF consumption. The nutrition education, along with training in livestock management, was offered with and without an intensive community-development component (described in more detail below). The study was designed to assess the relationship of the intervention on child growth and diet. We found improved dietary intake among children whose families received the nutrition education (Thorne-Lyman et al., 2019; Miller et al., 2020a, b), especially among those who also received community-development inputs. However, we did not assess the associations between ASF consumption and growth, nor the relationship of specific ASF to child growth. Furthermore, we limited our assessments to children $<60$ mo of age and did not directly compare the relationship of diet to growth between children of different ages. To address these areas, as well as some of the research gaps cited above, we conducted an observational study, leveraging an expanded version of this Banke data set. In the study reported here, we investigated the relationship of diet - specifically ASF - on child growth in rural Nepal, and controlled for intervention status and time (and other factors) in regression analyses.

\section{METHODS}

\section{Ethics}

This investigation was approved by the Nepal Health Research Council, as well as the Human Investigation Review Board of Tufts University, and was registered at ClinicalTrials.gov (NCT03516396). 


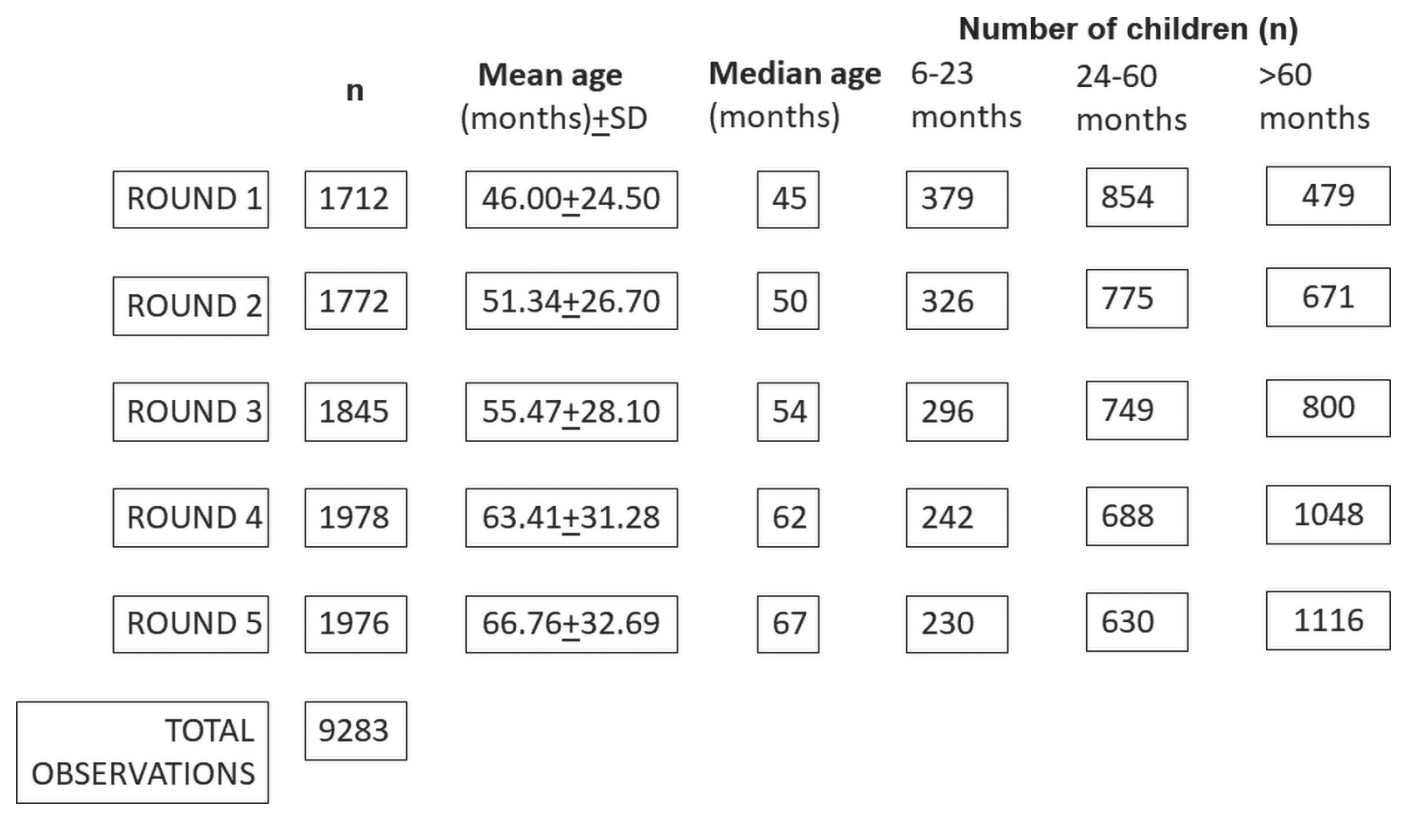

Figure 1. Number of children $>6$ mo of age seen at each of the 5 rounds of data collection over 3 yr. The mean \pm SD age (mo) and median age at each of the 5 rounds is shown, along with the number of children in each of the 3 age groups (6-23 mo, 24-60 mo, and >60 mo). Children aged during the study, explaining the increase in number from round 1. A total of 9,283 observations (paired growth and diet information) were obtained.

\section{Study Design}

This study of child growth and diet was nested within a longitudinal controlled impact evaluation trial (Habicht et al., 1999) implemented by Heifer International Nepal in Banke district in western Nepal, an area in the Terai (plains region) largely populated by lowincome subsistence farmers. Heifer International Nepal is a nongovernmental organization concerned with poverty alleviation via livestock management practices and community empowerment. This larger study was designed to assess the contributions of in-depth community mobilization activities plus training in family nutrition and livestock management on household sociodemographic outcomes and child growth and diet. The nutrition curriculum promoted diet diversity, ASF consumption, and food hygiene. Three nonadjacent communities from the same agroecological zone were identified based on similar sociodemographic characteristics. The communities were randomly assigned to 1 of 3 conditions: (1) full Heifer International Nepal intervention package, including community development, livestock management training, and nutrition education (full package); (2) livestock management training and nutrition education only (partial package); or (3) control (no inputs; further details are provided in Miller et al., 2020a). Five household visits were conducted between 2013 and 2016. Visit intervals ranged from 6 to 7 mo (except for a 12-mo interval between visits 3 and 4 due to a major earthquake). Three visits were conducted in the preharvest season and 2 in the postharvest season. At each visit, household demographics, child diet information, and child anthropometry were collected (described below).

\section{Participants}

All 1,805 children between the ages of 1 mo and 8 yr residing in participating households were enrolled in the study; 1,712 were $\geq 6$ mo of age. (Children $<6$ mo of age were excluded from analyses as the majority of these children were exclusively breast-fed.) Children were enrolled as they "aged-in" to the study (Figure 1); enrolled children were followed until the end of round 5. Accordingly, the mean age of the enrolled children increased over the course of the study.

Analyses were conducted by age group. Age groups were defined as 6 to $23 \mathrm{mo}, 24$ to $60 \mathrm{mo}$, and >60 mo (Figure 1). Of the 1,712 children at baseline, 1,339 completed 5 visits $(78 \%)$ and were considered separately in some analyses. Of the remaining 373 children, 155 completed 4 visits (9\%), 77 completed 3 visits (4\%), 49 completed 2 visits (3\%), and 92 completed 1 visit (5\%). There were 230 children aged 6 to 23 mo at the final round; all had 3 or fewer visits $(36 \%, 3$ visits; $60 \%, 2$ visits; and 3\%, 1 visit).

Child age was determined by inspection of the birth or the vaccine certificate. Children with physical or neu- 
rologic handicaps that prevented ingestion of a normal diet for their age or children with severe intercurrent illnesses at the time of survey were excluded.

\section{Anthropometry}

Child growth was assessed at each field visit. Weight was measured with Seca 835 electronic scales (Hamburg, Germany), calibrated before each measurement. Standing height $(>2 \mathrm{yr}$ ) was measured with a portable Seca 213 stadiometer; supine height ( $\leq 2 \mathrm{yr}$ ) was measured with a Seca BabyMat 210. Head circumference was assessed with disposable paper tapes at the maximum occipito-frontal measurement. Mid-upper arm circumference was measured with disposable insertion tapes (Harlow Ltd., South Shields, UK) on children $<60$ mo of age. Measurements were obtained twice, and results were averaged. If results were $>5 \%$ discrepant, then a third measurement was obtained. Results were converted to Z-scores (height for age, HAZ; weight for age, WAZ; head circumference for age, HCZ; midupper arm circumference for age, MUACZ) using WHO Anthro (World Health Organization, 2011) or WHO Anthro Plus for older children. The WHZ scores were calculated for children $<60$ mo; for children $>60$ mo, body mass index z-score (BAZ) was used. The prevalence of underweight, stunting, and wasting was determined according to World Health Organization standards (World Health Organization, 2011).

\section{Diet}

At each round, respondents were asked whether each enrolled child in the household had consumed any of 12 specific foods or food groups within the past $24 \mathrm{~h}$ (Kennedy et al., 2013). This information was used to calculate the number of ASF (meat, fish, offal, eggs, milk, other dairy products; range 0-6) consumed in the previous $24 \mathrm{~h}$ by each child at each round (Ruel, 2003b; Steyn et al., 2006). The sums for the 5 rounds were totaled (range 0-30) and then dichotomized to indicate whether the child had consumed any ASF at any of the 5 rounds ("one or more ASF consumed" versus "no ASF consumed").

The 12 foods or food groups were also aggregated into 8 categories, coded as "yes" or "no" for each round: (1) milk and other dairy products; (2) meat, offal, and fish; (3) eggs; (4) starchy staples (grains and white potatoes); (5) vitamin A-rich fruits and vegetables, including leafy greens; (6) other fruits and vegetables; (7) legumes, nuts, and seeds; and (8) oils (Swindale and Bilinsky, 2006). These "yes-no" categories for milk, meat, and eggs were used from each round in the analyses, paired with the corresponding growth mea- surements. A dietary diversity score (DDS; range 0-8) was constructed at each round based on the number of categories consumed.

For regression analysis, traditional DDS could not be used to assess the effect of other dietary components because this measure was colinear with the individual ASF variables used. Accordingly, the variable "sum non-ASF food categories" was devised, comprising the number of the following food groups consumed at each survey round: starchy staples; vitamin A-rich fruits and vegetables, including leafy green vegetables; other fruits and vegetables; legumes, nuts, and seeds; and oils (range $0-5$ ).

\section{Household Demographic Characteristics}

Demographic information (household wealth, land and animal ownership, annual income) was collected at each survey round from each household. Baseline information also included maternal education. Household wealth scores were derived from a principal component analysis of household possessions and quality of housing (e.g., toilet and water facilities) following DHS-Nepal guidelines (Ministry of Health Nepal et al., 2017). Animal ownership was determined by asking the respondent in each household how many immature and mature cows, buffalos, sheep, goats, pigs, chickens, and other poultry they owned. These results were converted to a standardized score using FAO Global Livestock Units (Food and Agricultural Organization, 2003). Annual income per household and per capita (Nepali rupees) and amount of land owned $\left(\mathrm{m}^{2}\right)$ were collected as additional indicators of household wealth. The level of maternal education was classified as (1) none or simple literacy classes, (2) some or completed primary school, and (3) some or completed secondary school (or beyond).

\section{Statistical Analysis}

The original sample size of 505 was calculated to detect a difference of $\geq 0.25$ in mean WAZ, with a power of $80 \%$ and a 2 -sided significance level of $<0.05$ in children $\leq 60$ mo of age in the original Banke intervention trial. The present analysis included children from all 3 arms of this trial. Data were entered and analyzed with JMP 13.1 (SAS Institute Inc., Cary, NC) and Stata (version 15.0; StataCorp LLC, College Station, TX). Analysis was conducted at the community, household, and individual levels, starting with a descriptive analysis of the variables, including $t$-tests and ANOVA with Bonferroni post hoc tests to correct for multiple comparisons, followed by a series of chi-squared tests and correlations to assess collinearity. Dependent variables were evalu- 
ated with histograms to verify normal distribution. As these data were collected over a 3 -yr period, some results are presented by round to provide a picture of the dynamic nature of children's growth and diet over the observation period. Mixed-effect linear regression models (using the Stata command "xtmixed") were used to study the association between consumption of dairy, meat, or eggs and anthropometric z scores (for younger children: HAZ, WAZ, WHZ, HCZ, and MUACZ; for older children HAZ, WAZ, HCZ, BAZ) with study group assignment, survey round, and its interaction as fixed effects, and household clustering as random effects. Growth parameters were linked to "yes-no" consumption of milk, meat, or egg categories at each round. Study group assignment was included as an adjustment, as our previous analysis of the intervention trial showed differences in diet intake related to study arm (Miller et al., 2020a). The regressions also controlled for time and for the interaction of time and exposure to the intervention. The model also included additional control variables including household (animal score, wealth, land ownership, income, and maternal education) and child factors (age, sex, relevant baseline anthropometric measurement).

\section{RESULTS}

\section{Baseline Household and Child Characteristics}

The characteristics of the study population at baseline are shown in Table 1 for the entire sample and by age group. In general, households were disadvantaged, with low incomes and few material possessions. Few of the mothers had received formal education. Households of younger children had higher wealth asset scores $(P=$ $0.01)$ and more educated mothers $(P=0.002)$.

At baseline, the children were undernourished: stunting and underweight were found in $>40 \%$ of children (Table 1). Growth status varied between the age groups. Compared with both younger and older children, stunting was more common among children 24 to 60 mo of age $(P=0.003)$; HAZ scores (mean $\pm \mathrm{SD})$ were also lower compared with younger or older children (respectively, $-1.97 \pm 1.53$ vs. $-1.78 \pm 1.55$ and $-1.80 \pm 1.24$, $P=0.04)$, reflecting growth faltering often observed at this age. More older children $(>60 \mathrm{mo})$ were underweight $(P<0.0002)$ and microcephalic $(P<0.0001)$, and had lower mean WAZ $(P<0.0001)$ and HCZ $(P=$ 0.0001) scores, compared with both groups of younger children.

Diet was generally poor at baseline, with most children consuming only $\sim 3$ to 4 food groups per day. Only $\sim 10 \%$ had consumed $>5$ food groups in the prior $24 \mathrm{~h}$. Younger children had lower DDS than older children $(P$
$<0.0001)$. The number of ASF consumed per day was low in all age groups, averaging between 0.48 to 0.56 . Likewise, only 20 to $26 \%$ of children had consumed milk during the prior $24 \mathrm{~h}$, and even fewer children consumed eggs (7-9\%). Meat consumption was also low, ranging from 12 to $23 \%$ : children $>23$ mo were more likely to consume meat than the youngest children in the study $(P=0.003)$. There were no significant differences in these measures of diet adequacy between the 3 study arms at baseline (data not shown).

\section{Growth Over 3 Years of Observation}

Over the 3-yr period of observation during the study, children's growth improved, but not dramatically (Figure 2). Although some individual children showed growth recovery, in general, anthropometric z-scores remained below -1.5 for all growth parameters (not shown). Between round 1 and round 5, stunting was reduced only in the children $>60$ mo $(P<0.0001)$. Underweight children decreased in all 3 age groups (6-23 mo, $P=0.02 ; 24-60$ mo, $P<0.0001 ;>60$ mo, $P$ $<0.0001)$. Microcephaly was reduced only among the older children $(P<0.0001)$.

\section{Diet Over the Course of the Study}

Diets remained generally limited over the course of the study, although some improvements were observed. Consumption of ASF varied by age group: the number of ASF consumed almost doubled in children aged 24 to 60 and $>60$ mo (respectively, from $0.54 \pm 0.75$ to 1.03 \pm 0.96 , and from $0.56 \pm 0.77$ to $1.05 \pm 0.98$; both $P<$ 0.0001 ), with less, but still significant, improvement in the 6 to 23 mo age group from $0.48 \pm 0.71$ to $0.78 \pm$ $0.84, P<0.0001$ (Figure 3A). The percentage of children who consumed at least $1 \mathrm{ASF}$ also increased over time $(+17$ to $+26 \%$; Figure $3 \mathrm{~B})$. In contrast, there was little change in the percentage of children consuming milk $(-3 \%$ to $+7 \%$; Figure 3C).

Over 9,283 observations, ASF were consumed infrequently: milk at $28 \%$, meat at $27 \%$, and eggs at $15 \%$. Consumption of all 3 categories of ASF increased from baseline to endline (eggs from 9 to $19 \%$, meat from 19 to $39 \%$; both $P<0.0001$ ), although milk consumption remained relatively static (from 22 to $27 \% ; P=0.002$; Figure 4).

In accordance with the increasing age of the enrolled children, breast milk consumption declined steadily over the 5 survey rounds, from $36 \%$ of children at baseline to $19 \%$ at round 5 (not shown). There was no relationship between being breast-fed and consuming dairy products. 
Table 1. Baseline characteristics of study population ${ }^{1}$

\begin{tabular}{|c|c|c|c|c|c|}
\hline Item & $\begin{array}{l}\text { All children } \\
(\mathrm{n}=1,712)\end{array}$ & \multicolumn{3}{|c|}{ Age group } & $P$-value \\
\hline \multicolumn{5}{|l|}{ Study area $(\%)$} & \multirow[t]{3}{*}{ NS } \\
\hline Control & 32 & 33 & 32 & 30 & \\
\hline Intervention & 28 & 29 & 28 & 29 & \\
\hline None or nonformal education & 79 & 74 & 78 & 84 & \multirow{3}{*}{0.002} \\
\hline At least some primary & 16 & 18 & 16 & 12 & \\
\hline At least some secondary & 5 & 8 & 5 & 3 & \\
\hline Land owned $\left(\mathrm{m}^{2}\right)$ & $7,268 \pm 11,943$ & $8,095 \pm 14,427$ & $7,286 \pm 11,666$ & $6,582 \pm 6,111$ & NS \\
\hline Animal ownership score & $1.77 \pm 2.15$ & $1.82 \pm 228$ & $1.77 \pm 2.09$ & $1.73 \pm 2.15$ & NS \\
\hline Wealth score & $0.003 \pm 1.02$ & $0.10 \pm 1.07$ & $0.01 \pm 1.04$ & $-0.09 \pm 0.96$ & 0.01 \\
\hline Annual income $(\mathrm{NPR})^{2}$ & $47,024 \pm 61,947$ & $45,698 \pm 66,958$ & $47,110 \pm 61,828$ & $47,915 \pm 58,046$ & NS \\
\hline $\mathrm{ASF}^{3}$ consumption & $0.54 \pm 0.075$ & $0.48 \pm 0.71$ & $0.53 \pm 0.74$ & $0.56 \pm 0.77$ & NS \\
\hline \multicolumn{6}{|l|}{$\%$ consuming any } \\
\hline ASF & 41 & 49 & 41 & 43 & NS \\
\hline Milk/dairy & 23 & 26 & 22 & 20 & NS \\
\hline Meat & 19 & 12 & 20 & 23 & 0.0003 \\
\hline Eggs & 9 & 7 & 9 & 9 & NS \\
\hline \multicolumn{6}{|l|}{ Child growth } \\
\hline Height for age z-score (HAZ) & $-1.88 \pm 1.40$ & $-1.78 \pm 1.55$ & $-1.97 \pm 1.53$ & $-1.80 \pm 1.24$ & 0.04 \\
\hline Weight for age z-score (WAZ) & $-1.87 \pm 1.04$ & $-1.83 \pm 1.11$ & $-1.79 \pm 1.04$ & $-2.05 \pm 1.00$ & $<0.0001$ \\
\hline Weight for height z-score (WHZ) & $-1.03 \pm 1.10$ & $-1.21 \pm 1.1$ & $-0.95 \pm 1.10$ & $\mathrm{NA}^{4}$ & 0.0001 \\
\hline Head circumference z-score (HCZ) & $-1.25 \pm 1.15$ & $-1.15 \pm 1.16$ & $-1.18 \pm 1.10$ & $-1.44 \pm 1.19$ & 0.0001 \\
\hline MUAC $^{5}$ z-score & $-1.13 \pm 0.92$ & $-1.08 \pm 1.01$ & $-1.15 \pm 0.88$ & NA & NS \\
\hline \multicolumn{6}{|l|}{$\%$ of children who were } \\
\hline Stunted $(\mathrm{HAZ}<-2)$ & 47 & 42 & 51 & 43 & 0.003 \\
\hline
\end{tabular}

${ }^{1}$ Values with a \pm symbol are means \pm SD.

${ }^{2} \mathrm{NPR}=$ Nepali rupees.

${ }^{3} \mathrm{ASF}=$ animal source foods

${ }^{4} \mathrm{NA}=$ not available.

${ }^{5} \mathrm{MUAC}=$ mid-upper arm circumference.

\section{Growth and Diet in Children With 5 Study Visits}

Next, growth was examined in relationship to ASF consumption in the subgroup of 1,339 children who had complete anthropometry and dietary information over all 5 rounds of data collection, and who were $\geq 6$ mo at round 1 . Of the 6,695 diet records, $53 \%$ indicated that the child had consumed ASF at least 1 time during the five 24 -h diet recalls ( $34 \%$ once, $14 \%$ twice, $4 \% 3$ times, and $1 \% 4$ or more times); $47 \%$ of diet records indicated no consumption of ASF (Table 2). Consumption of even a single ASF at any of the 5 surveys was associated with higher z-scores for all measurements (HAZ, $P=0.0008$; WAZ, $P<0.0001$; WHZ, $P=0.002$; HCZ, $P<0.0001$; MUACZ, $P<0.0001)$ and less stunting, underweight, wasting, and microcephaly (respectively,
$P=0.01, P<0.0001, P=0.01$, and $P<0.0001)$ compared with children who had not consumed a single ASF. Thus, consuming even a single ASF at any of the 5 surveys over the $3 \mathrm{yr}$ of the study was associated with better growth. When evaluated by age group, these findings were consistent in the children $>60$ mo but less consistent in the younger age groups.

We next assessed ASF consumption patterns by age group. Younger children consumed fewer eggs $(P<$ $0.0001)$ and less meat $(P<0.0001)$ but more milk $(P=$ 0.0002 ) than children 24 to 60 or $>60$ mo of age (Figure $5)$. However, these results did not control for household factors (e.g., wealth).

The relationship of consumption of specific ASF (meat, eggs, and milk) to the corresponding anthropometric z-scores was then examined. Results varied by 
survey round (Figure 6; for clarity only results for round 1 and round 5 are shown). Children who consumed milk had higher WAZ (round $1, P=0.05$; round $5, P=$ 0.03 ), $\mathrm{HCZ}$ (round $2, P=0.002$ ), and MUACZ (round $2, P=0.001)$. Children who had consumed meat had higher HAZ (round 5, $P=0.008$ ), WAZ (round $2 P=$ 0.001 ; round $4, P=0.002$ ), HCZ (round $2, P=0.005$ ), and MUACZ (round $4, P=0.008$ ). Children who consumed eggs had higher HAZ (round $4, P=0.0005$ ), WAZ (round $4, P=0.01$ ), HCZ (round $1, P=0.01$; round $3, P=0.006$; round $5, P=0.009)$, and MUACZ (round 2, $P=0.02$ ). Thus, the relation between consumption of specific ASF and growth parameters varied over time.

\section{Growth and Diet in Context of Household Characteristics}

To further explore the relationships between child diet and growth, mixed-effect linear regression analyses were performed (Table 3). The association of dairy, meat, and eggs with child growth was examined sepa- rately within each age group. Results for the oldest children (>60 mo) were strikingly different than for the younger age groups. Among children $>60$ mo of age, milk consumption related to both $\operatorname{HAZ}(\beta=0.030, P$ $<0.01)$ and WAZ $(\beta=0.034, P<0.01)$. That is, each survey at which the child consumed milk was associated with an increase of 0.030 in HAZ and an increase of 0.034 in WAZ. For each survey at which the child consumed eggs, WAZ increased by $0.032(P<0.05)$. Additionally, for each increase in the sum of non-ASF food categories, HCZ increased by $0.021(P<0.05)$.

For children ages 24 to 60 mo, milk consumption related to $\mathrm{HCZ}(\beta=0.044, P<0.01)$. However, no relationship to other dietary measures and growth parameters was found after adjustment. For the youngest age group (6-23 mo), intake of dairy, meat, or eggs did not relate to any of the anthropometric parameters measured.

Other variables also correlated with growth, including intervention-group assignment. The relation of group assignment to growth varied by round, age group, and specific growth parameter (Supplemental

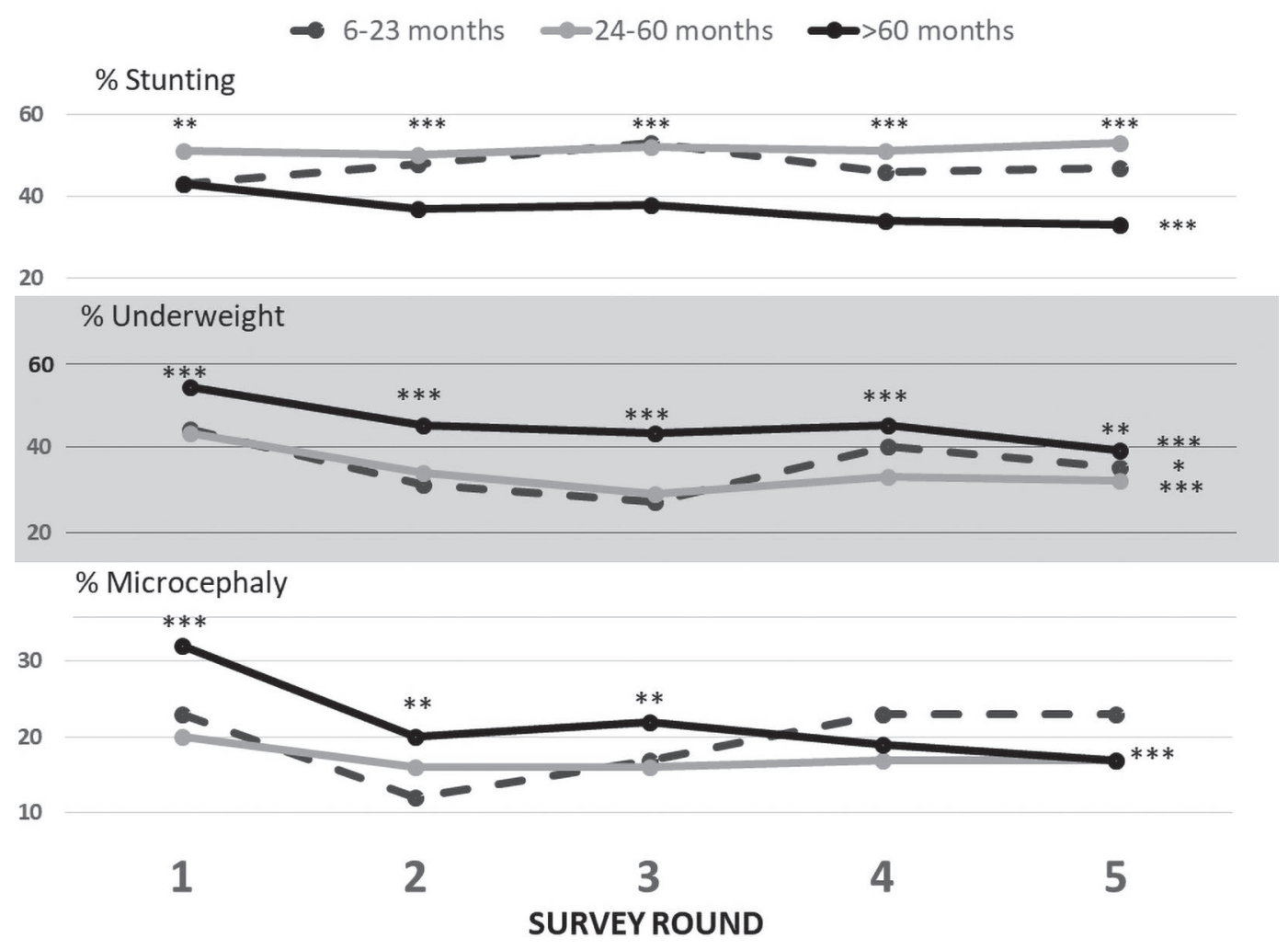

Figure 2. The percentage of children with stunting (top panel), underweight (gray middle panel), and microcephaly (lower panel) are shown at each survey round. Results are shown by age group (6-23 mo, dashed black line; 24-60 mo, gray line; and >60 mo, black line). Differences between the age groups at each round are shown by the asterisks above the lines. Differences from baseline (round 1 ) to endline (round 5 ) are shown by the asterisks right of the lines. ${ }^{*} P<0.05,{ }^{* *} P<0.01,{ }^{* * *} P<0.005$. 
Table S1; https://doi.org/10.3168/jds.2020-18289). For children 6 to 23 mo of age, groups assigned to the full package intervention were associated with higher WHZ, WAZ, and MUACZ but lower HCZ (respectively, $\beta=$ $0.415, P<0.05 ; \beta=0.258, P<0.05 ; \beta=0.393, P$ $<0.05$; and $\beta=-0.326, P<0.01$ ). For children 24 to $60 \mathrm{mo}$, participation in the full package intervention group was positively associated with WHZ, HAZ, MUACZ, and HCZ scores (respectively, $\beta=0.209, P$ $<0.05 ; \beta=0.247, P<0.01 ; \beta=0.566, P<0.01$; and $\beta=0.149, P<0.01)$. For children $>60 \mathrm{mo}$, this group assignment was positively associated with WAZ, HCZ, and BAZ (respectively, $\beta=0.124, P<0.01 ; \beta=$ $0.189, P<0.01$; and $\beta=0.145, P<0.05$ ). There were few growth relationships to assignment to the partial package intervention, only for higher MUACZ score in children 6 to $23 \mathrm{mo}$ and lower HCZ for children $>60 \mathrm{mo}$ (respectively, $\beta=0.203$ and -0.157 , both $P<0.01$ ). Thus, age group and household intervention status also related to child growth.
Other measured household and child characteristics, as well as time, had varying relationships with child growth (Supplemental Table S1). By far, the strongest association was between $\mathrm{Z}$-scores and the respective anthropometric measurements at baseline, with $\beta$ coefficients ranging from 0.748 to 0.929 .

\section{DISCUSSION}

In this 3-yr observational study, we leveraged a data set generated through a 3 -yr longitudinal controlledimpact evaluation of a community-development intervention to examine the relationship of ASF consumption to child growth in rural Nepal. Children in these communities were generally undernourished, with limited improvement in growth over time. Few ASF were consumed, although this increased over time. The ASF consumption patterns varied by age; the youngest children consumed more milk and less meat and eggs. Consumption of even a single ASF (as documented
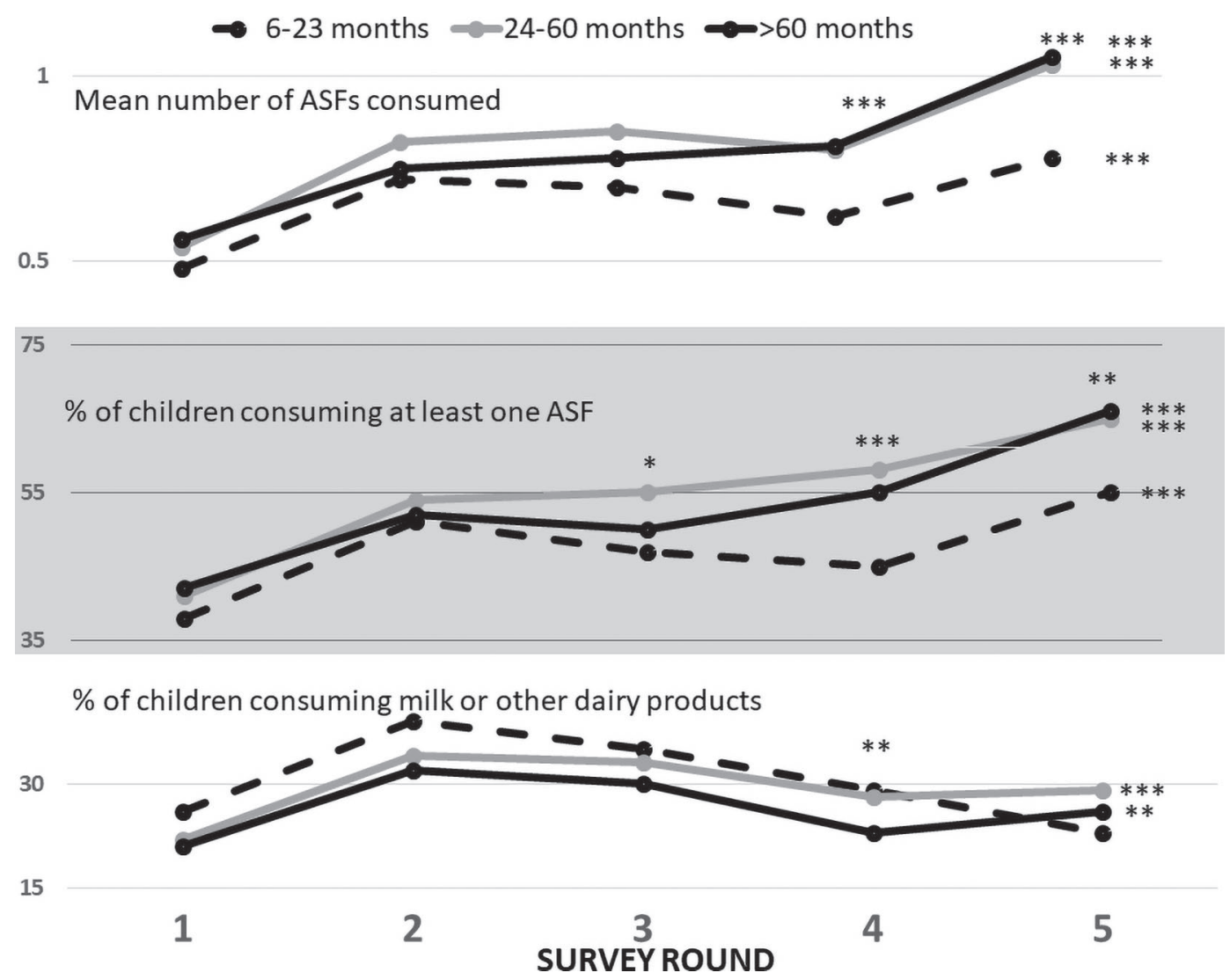

Figure 3. Dietary indicators are shown by survey round and by age group (6-23 mo, dashed black line; 24-60 mo, gray line; and >60 mo, black line). The top panel shows the mean number of animal source food (ASF) consumed, the middle panel shows the percentage of children consuming at least $1 \mathrm{ASF}$, and the bottom panel shows the percentage of children consuming at least 1 item in the "milk" category (comprising milk or other dairy products). Differences between the age groups at each round are shown by the asterisks above the lines. Differences from baseline (round 1) to endline (round 5) are shown by the asterisks right of the lines. ${ }^{*} P<0.05,{ }^{* *} P<0.01,{ }^{* * *} P<0.005$. 


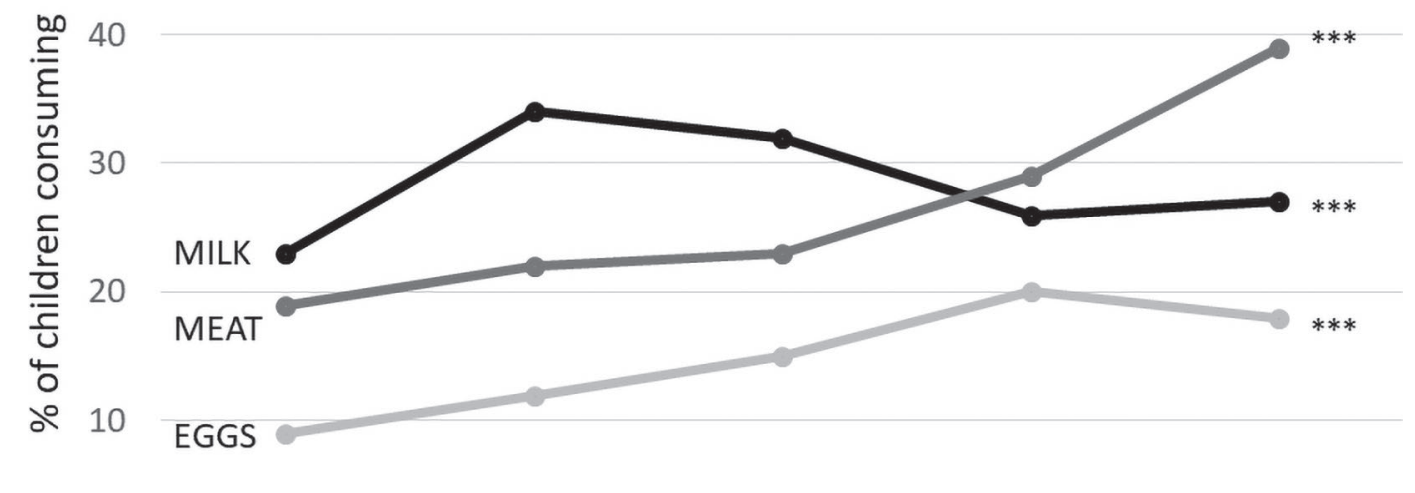

0

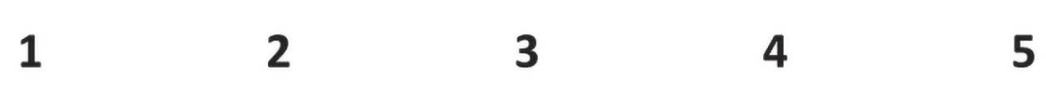

\section{SURVEY ROUND}

Figure 4. The consumption of milk, meat, and eggs varied by round. The percentage of children consuming milk at each round is shown by the black line, meat by the dark gray line, and eggs by the light gray line. There was an increase in consumption from baseline (round 1 ) to endline (round 5 ) for each of these food categories. ${ }^{* * *} P<0.005$.

during any of the 5 study rounds) was associated with higher WAZ, WHZ, HCZ, and MUACZ scores, as well as less wasting and underweight.

However, after adjustment of household and child factors, including study arm assignment, relationships between consumption of specific ASF and child growth were limited. For children $>60$ mo of age, milk consumption was associated with higher HAZ $(\beta=0.030$, $P<0.01)$ and higher WAZ $(\beta=0.034, P<0.01)$ scores, and egg consumption was associated with higher WAZ $(\beta=0.032, P<0.01)$. For children 24 to $60 \mathrm{mo}$, milk consumption was associated with higher $\mathrm{HCZ}(\beta$ $=0.044, P<0.01)$. Thus, for each additional day of consuming these items (out of the 5 surveys), the zscore increased by $\sim 0.03$ to 0.04 . In contrast, no relation between consumption of any specific ASF and growth was seen in the youngest children (6-23 mo). Meat consumption did not relate to any of the measured growth parameters in any of the 3 age groups; it is possible that the quantities of meat consumed were insufficient to contribute to growth (Ruel, 2003a). Likewise, the lack of association of milk intake with growth in the youngest age groups may reflect a threshold effect.

Many studies have investigated the relationship of child diet, especially ASF consumption, to growth. Several recent meta-analyses and systematic reviews have emphasized that it is sometimes difficult to demonstrate definitive relationships (Headey et al., 2017; Eaton et al., 2019; Pimpin et al., 2019; Shapiro et al., 2019). For example, Shapiro et al. (2019) found limited evidence that ASF consumption reduced stunting and that the relationships between ASF and the secondary indicators length (height), weight, head circumference, and anemia were largely nonsignificant. In contrast, Pimpin et al.'s (2019) systematic review and meta-analysis of 62 controlled trials comprising more than 30,000 participants across 5 continents confirmed these findings on stunting, but in contrast found that dietary animal proteins generally increased weight in children. Eaton et al. (2019) judged the evidence for ASF (vs. fortified cereals or none) contributing to improved growth as "low quality," noting that the evidence for meat intake (vs. dairy) improving linear growth and weight gain as "moderate quality." The latter 2 studies focused on diet interventions, but in Headey et al.'s (2017) study (and to some extent in the study by Shapiro et al., 2019) data reflected the natural diets consumed by the children. In undernourished children, certain dimensions of growth may be prioritized when adequate calories become available (e.g., weight is likely to improve before linear growth). Thus, it is not surprising to find these differential relationships in undernourished populations.

An additional complexity in drawing conclusions, particularly in naturalistic studies that group all ASF together, derives from the important nutritional variations among ASF (Murphy et al., 2003). For example, milk contains more vitamin $\mathrm{B}_{12}$, vitamin $\mathrm{A}$, riboflavin, folate, calcium, and various stimulating growth factors, 
but is low in iron. In comparison, meat is a rich source of heme iron, zinc, riboflavin, and vitamin $\mathrm{B}_{12}$ (Dror and Allen, 2011). Eggs contain high-quality protein, essential unsaturated fatty acids, phosphorus, trace minerals, vitamins $\mathrm{A}, \mathrm{D}, \mathrm{E}$, and $\mathrm{K}$, and many watersoluble $\mathrm{B}$ vitamins including $\mathrm{B}_{12}$, but are low in calcium (Watkins, 1995). Yet, some reviews analyze ASF consumption as a single entity (Pimpin et al., 2019; Shapiro et al., 2019). Other studies have examined the differential relationships of milk, meat, eggs, or isocaloric equivalents to particular growth parameters (Mal- colm, 1970; Neumann et al., 2003; Whaley et al., 2003; Grillenberger et al., 2006; Neumann et al., 2007; Allen and Dror, 2011; Michaelsen et al., 2011). For example, in the comprehensive controlled trial of meat versus dairy versus energy-equivalent supplements provided to Kenyan school children, increases in height among children who received milk supplements were found only in those who were younger and stunted (Neumann et al., 2003; Grillenberger et al., 2006). Thus, children with various patterns of undernutrition may respond differently at different ages to various dietary components.

Table 2. Growth parameters ${ }^{1}$ of children in relation to whether or not they had consumed at least 1 animal source food (ASF) at any time during the 5 periods of data collection, by age group; all children were seen at each of the 5 rounds

During 5 rounds of data collection:

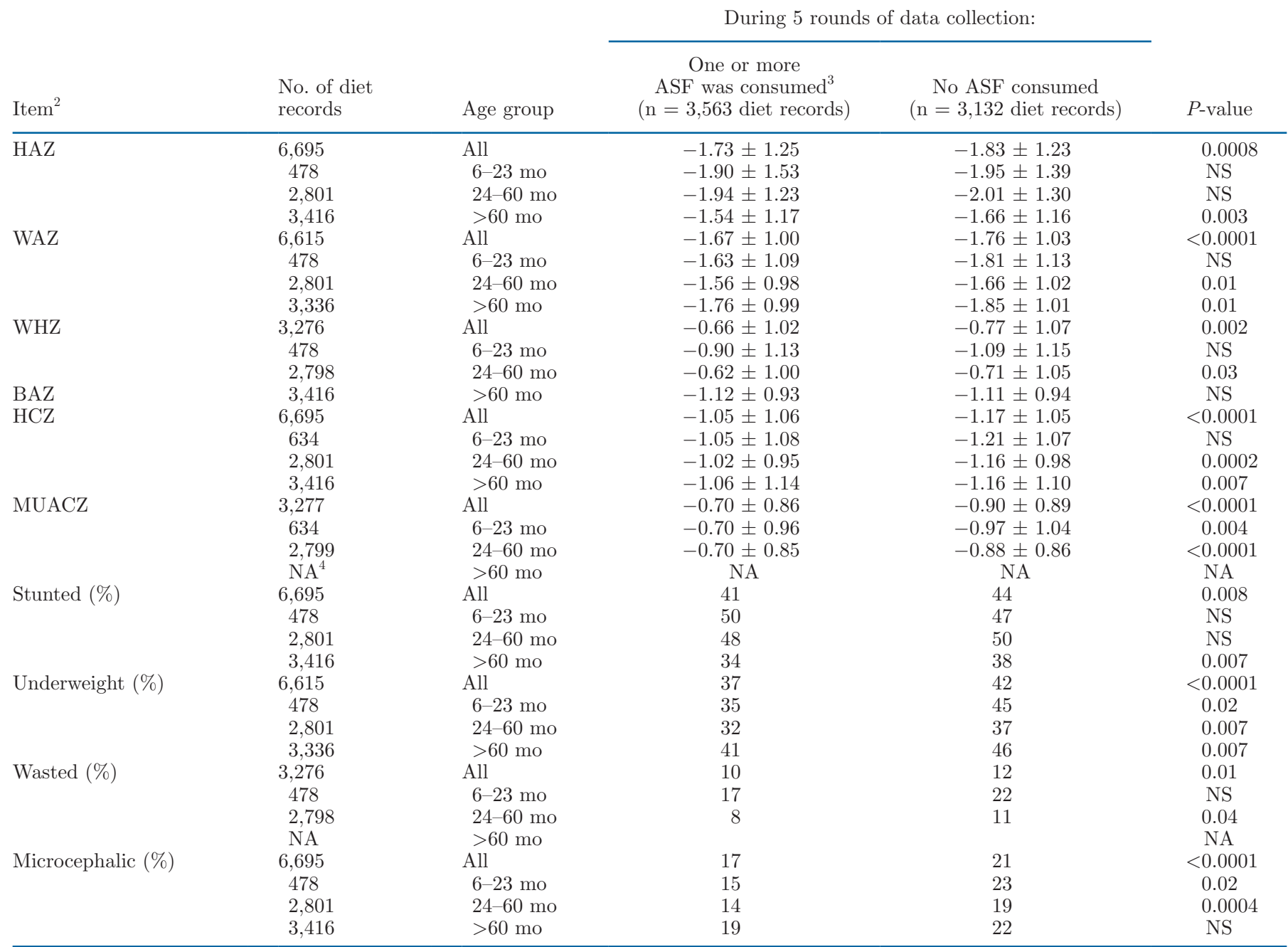

${ }^{1}$ Values with a \pm symbol are means \pm SD.

${ }^{2} \mathrm{HAZ}=$ height for age $\mathrm{z}$-score; WAZ = weight for age z-score; WHZ = weight for height $\mathrm{z}$-score; HCZ = head circumference z-score; MUACZ = mid-upper arm circumference z-score; BAZ = body-mass-index z-score.

${ }^{3} \mathrm{ASF}$ consumption was determined at each of the 5 rounds of data collection. The sums for each of the 5 rounds were then added together (range 0-30) and dichotomized to indicate if the child had consumed any ASF at any of the 5 rounds ("one or more ASF consumed" versus "no ASF consumed").

${ }^{4} \mathrm{NA}=$ not available. 
Milk has been particularly cited for its benefits in treating children with undernutrition (Michaelsen et al., 2011). Milk is also the most common ASF consumed by children in developing countries worldwide (Headey et al., 2017). In an analysis of Demographic and Health Survey data from 7 countries in Latin America, milk intake was significantly associated with better HAZ and WAZ in all countries, whereas meat intake showed this association in only 1 country (Ruel, 2003a). In a recent review, Bolton (2019) stated that milk and meat were better at reducing stunting than eggs.

Consumption of ASF is only one facet of diet; diet diversity also contributes to growth outcomes. Headey has estimated that consuming vegetables, legumes and nuts, or fruit reduces stunting by 1.1 to $2.7 \%$ compared with not consuming these items (Headey, 2018). Other dietary factors must also be considered. For example, consumption of phytates, high fiber, or other inhibitors may alter absorption or utilization of the nutrients contained in ASF (Dror and Allen, 2011).

Furthermore, many factors in addition to diet contribute to child growth. In a recent study, the number of prenatal visits, household wealth, age of mother (teenage vs. adult), access to medical facility, improved household latrine, and maternal education $>9$ yr reduced the risk of stunting from 3.8 to $8.2 \%$ (Headey, 2018). Child age is also important; linear, ponderal, and brain growth rely on different nutrients at various times during childhood. Diet content typically changes over time in early life and there is evidence that ASF may have different effects at different ages (Headey et al., 2017; Pimpin et al., 2019). As we found, child growth status at the start of any investigation is important to consider in analyses.

Household context also contributes to child growth. We found that exposure to a community-development intervention, combined with a nutrition education program, was associated with higher anthropometric Z-scores (WHZ and BAZ for all 3 age groups, HCZ for children 24-60 mo and >60 mo, WAZ for children 6-23 mo and >60 mo, and MUACZ for children 24-60 mo and $>60 \mathrm{mo}$ ). However, it was notable that despite the nutrition education provided to mothers in both the full package and partial package intervention groups, ASF consumption was limited overall. Only $53 \%$ of children consumed 1 or more ASF over the 5 study rounds. Even for families who recognize the importance of ASF in children's diets, these nutrients may not be accessible. Availability and affordability clearly influence choices families make about food for themselves and their children (Eaton et al., 2019). Although most of these subsistence farmers owned animals, sale of meat, eggs, or dairy products may have been prioritized over household consumption (Bwibo and Neumann, 2003; Smith et al., 2013). Even after adjustment for wealth and other household factors, the number and

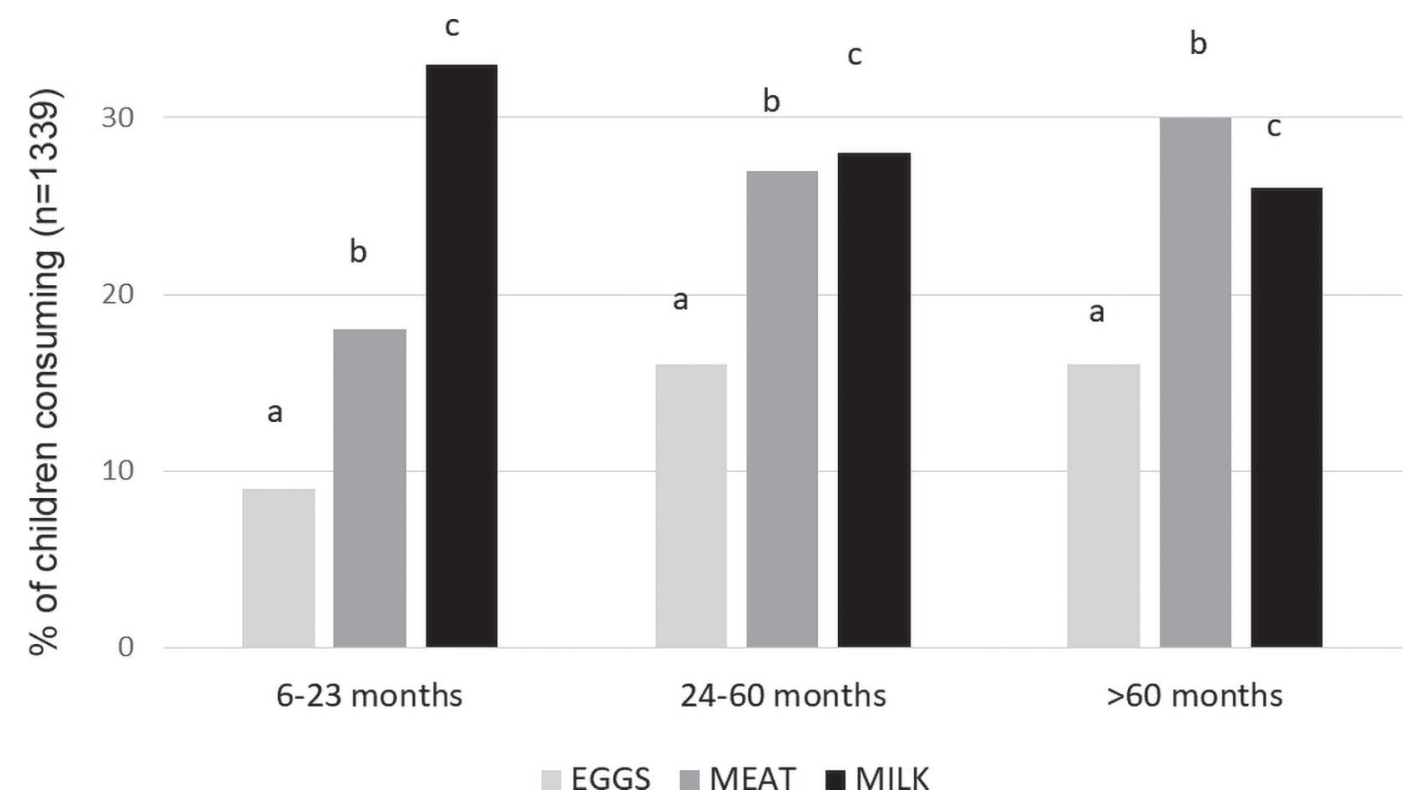

Figure 5. The percentage of the 1,339 children seen at all 5 study rounds who consumed eggs (light gray bars), meat (dark gray bars), and milk (black bars) is shown by age group. Comparison of consumption of each food category between age groups is indicated by "a" (eggs), "b" (meat), and "c" (milk). Younger children consumed fewer eggs $(P<0.0001)$ and less meat $(P<0.0001)$ but more milk $(P=0.0002)$ than children $24-60$ or $>60$ mo of age. 


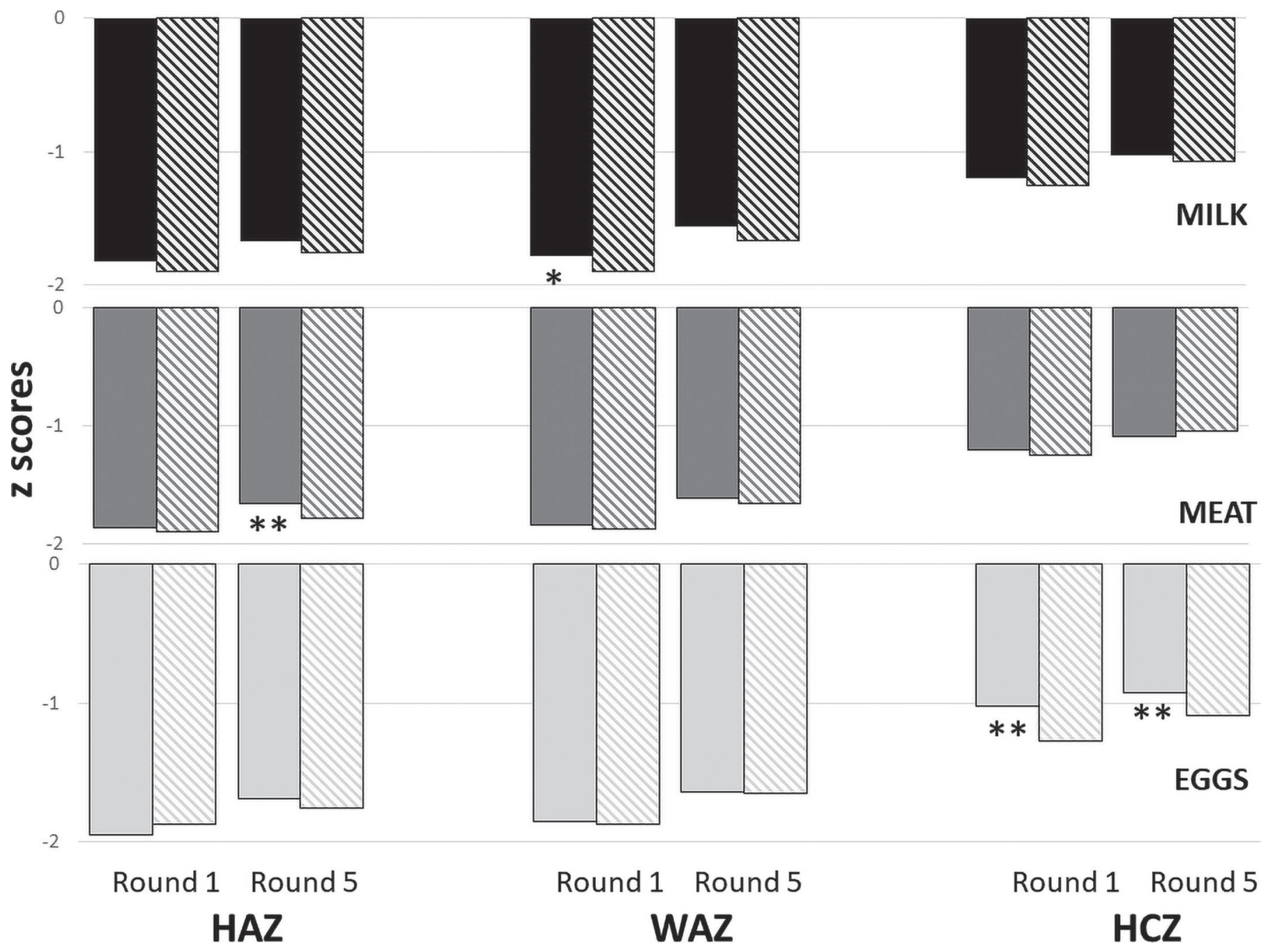

Figure 6. Z-Scores for height (HAZ), weight (WAZ), and head circumference (HCZ) are shown in relation to animal source food consumption (top panel = milk, middle panel = meat, lower panel = eggs). Results for children who consumed the item are shown in the solid bars; for those who did not consume the item, results are shown in the hatched bars. Only results from round 1 and round 5 are shown for clarity. $\mathrm{n}=$ 1,712 for round $1, \mathrm{n}=1,976$ for round $5 .{ }^{*} P<0.05,{ }^{* *} P<0.01$

type of livestock owned may also directly relate to what is offered to children to consume (Broaddus-Shea et al., 2020).

Our study had several important limitations. We recognize that the 24-h recall questionnaire, although perhaps the most widely used tool for population surveys, has important shortcomings. The information collected simply documents whether or not the child ate a specific item in the prior $24 \mathrm{~h}$. No information is included about the frequency or quantity consumed; foods in mixed dishes may be complicated to assess (Shapiro et al., 2019). Availability of these details would greatly enhance the ability to assess the adequacy of the child's diet in a more comprehensive manner. In addition, the recall period of $24 \mathrm{~h}$ does not necessarily provide an accurate characterization of the child's normal diet, as it is subject to random within-person error (ThorneLyman et al., 2014), social desirability bias, and other sources of error (Gibson et al., 2017). These factors hamper the ability to understand the relationship between diet and growth outcomes. It is possible that more frequent and more complete diet records could have revealed stronger (or different) relationships than the small increases we found in our adjusted analyses. Also, we recognize that unmeasured variables at the individual, household, and community levels may have affected child outcomes, and that there was potential for residual confounding by factors not included in the regression models. For example, unmeasured household factors may have contributed to differential responses to the offered interventions or to the general conditions in Nepal over this time period, including the 
Miller et al.: MILK SYMPOSIUM: MILK PRODUCTION IN DEVELOPING COUNTRIES

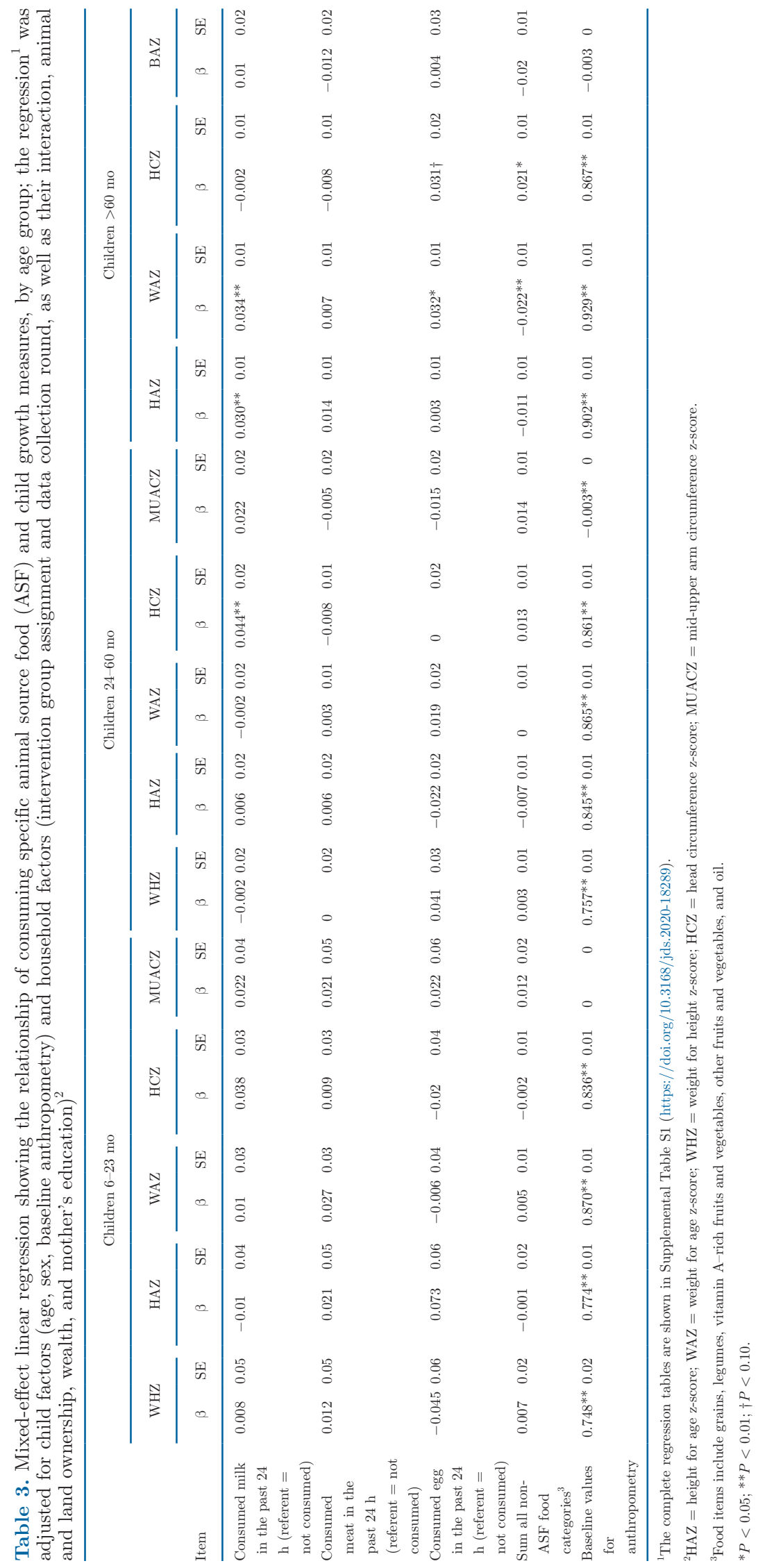


major earthquake. Likewise, household practices may have been influenced by other programs in these project areas (although none were specifically identified). We attempted to address some of these issues by controlling for intervention group assignment, time, and other household factors in the regression analyses, as previous analyses had shown the importance of these variables (Miller et al., 2020a). We also recognize that the original study was designed to answer a different research question. We used an expanded version of that data set to conduct this observational study, which we recognize can generate only associations, and not causal relationships.

Our study had several strengths. The relatively large sample of children followed longitudinally allowed detailed analysis of results by age group and by survey round over several seasons. Complete household information, including maternal and socio-economic characteristics, were also included, and 1,339 children had complete diet records, anthropometry, and household information over $3 \mathrm{yr}$ of data collection. We were also able to include children with a broad range of ages, allowing for a comparison of 3 distinct age groups: children 6 to $23 \mathrm{mo}, 24$ to $60 \mathrm{mo}$, and $>60 \mathrm{mo}$ of age. The different patterns of growth responses to ASF consumption at different ages emphasizes the complexities of understanding the relationships of diet and growth in resource-poor settings.

In conclusion, the most striking findings in our study indicated a relationship between dairy consumption and child WAZ and HAZ, but only for those children $>60$ mo of age. In rural Nepal, milk may be a key ASF to target to promote growth. Further investigation of milk-consumption practices in this setting are warranted to better understand the age-specific relationships observed as well as to address barriers to consumption of milk and other ASF among undernourished children.

\section{ACKNOWLEDGMENTS}

Support for this effort was provided jointly by the Feed the Future Innovation Lab for Nutrition, which is funded by the United States Agency for International Development (USAID) under grant ID AIDOAA-L-1-00006 and by the United States Agency for International Development (USAID) Bureau for Food Security under Agreement AID-OAA-L-15-00003 as part of Feed the Future Innovation Lab for Livestock Systems (University of Florida, Gainesville). Travel to the meeting was funded by the American Dairy Science Association. The authors express their gratitude to Heifer Nepal field staff (Banke District, Nepal), Valley Research field enumerators (Kathmandu and Banke District, Nepal) and the families and children (Banke
District, Nepal) who participated in this research. We also thank Andrew Thorne-Lyman (Johns Hopkins University, Baltimore, MD) for his thoughtful review of this manuscript. Any opinions, findings, conclusions, or recommendations expressed here are those of the authors alone. The authors have not stated any conflicts of interest.

\section{REFERENCES}

Allen, L. H. 1993. The nutrition CRSP: What is marginal malnutrition, and does it affect human function? Nutr. Rev. 51:255-267. https://doi.org/10.1111/j.1753-4887.1993.tb03117.x.

Allen, L. H., and D. K. Dror. 2011. Effects of animal source foods, with emphasis on milk, in the diet of children in low-income countries. Pages 113-130 in Milk and Milk Products in Human Nutrition. Vol. 67. R. A. Clemens, O. Hernell, and K. F. Michaelsen, ed. Nestec Ltd., Vevey/S. Karger AG, Basel, Switzerland.

Bhutta, Z. A., R. L. Guerrant, and C. A. Nelson III.. 2017. Neurodevelopment, nutrition, and inflammation: The evolving global child health landscape. Pediatrics 139(Suppl. 1):S12-S22. https://doi .org/10.1542/peds.2016-2828D.

Bolton, L. 2019. Animal sourced foods (ASF): Evidence on stunting and programmes to increase consumption. Pages 1-10 in K4D Helpdesk Report 651. Institute of Development Studies, Brighton, UK.

Broaddus-Shea, E. T., S. Manohar, A. L. Thorne-Lyman, S. Bhandari, B. A. S. Nonyane, P. J. Winch, and K. P. West Jr.. 2020. Smallscale livestock production in Nepal is directly associated with children's increased intakes of eggs and dairy, but not meat. Nutrients 12:252. https://doi.org/10.3390/nu12010252.

Bwibo, N. O., and C. G. Neumann. 2003. The need for animal source foods by Kenyan children. J. Nutr. 133(Suppl. 2):3936S-3940S. https://doi.org/10.1093/jn/133.11.3936S.

Closa-Monasterolo, R., J. Escribano Subias, V. Luque Moreno, and N. Ferré Pallas. 2017. Early nutrition: Effects of specific nutrient intake on growth, development, and long-term health. Pages 105-129 in Early Nutrition and Long-Term Health-Mechanisms, Consequences, and Opportunities. J. M. Saavedra and A. M. Dattilo, ed. Elsevier, Philadelphia, PA.

Darrouzet-Nardi, A. F., L. C. Miller, N. Joshi, S. Mahato, M. Lohani, and B. L. Rogers. 2016. Child dietary quality in rural Nepal: Effectiveness of a community-level development intervention. Food Policy 61:185-197. https://doi.org/10.1016/j.foodpol.2016.03.007.

Dror, D. K., and L. H. Allen. 2011. The importance of milk and other animal-source foods for children in low-income countries. Food Nutr. Bull. 32:227-243. https://doi.org/10.1177/156482651103200307.

Eaton, J. C., P. Rothpletz-Puglia, M. R. Dreker, L. Iannotti, C. Lutter, J. Kaganda, and P. Rayco-Solon. 2019. Effectiveness of provision of animal-source foods for supporting optimal growth and development in children 6 to 59 months of age. Cochrane Database Syst. Rev. 2:CD012818. https://doi.org/10.1002/14651858 .CD012818.pub2.

Food and Agricultural Organization. 2003. Compendium of Agricultural-Environmental Indicators. Statistics Analysis Service, Statistics Division, Food and Agriculture Organization of the United Nations, Rome, Italy.

Gibson, R. S., U. R. Charrondiere, and W. Bell. 2017. Measurement errors in dietary assessment using self-reported 24-hour recalls in low-income countries and strategies for their prevention. Adv. Nutr. 8:980-991. https://doi.org/10.3945/an.117.016980.

Grillenberger, M., C. G. Neumann, S. P. Murphy, N. O. Bwibo, R. E. Weiss, L. Jiang, J. G. Hautvast, and C. E. West. 2006. Intake of micronutrients high in animal-source foods is associated with better growth in rural Kenyan school children. Br. J. Nutr. 95:379-390. https://doi.org/10.1079/BJN20051641.

Habicht, J. P., C. G. Victora, and J. P. Vaughan. 1999. Evaluation designs for adequacy, plausibility and probability of public health 
programme performance and impact. Int. J. Epidemiol. 28:10-18. https://doi.org/10.1093/ije/28.1.10.

Headey, D. 2018. Animal Sourced Foods and Child Nutrition in South Asia: Policy Priorities. Leveraging Agriculture for Nutrition in South Asia (LANSA) policy brief. Issue 11. Department for International Development, London, UK.

Headey, D., K. Hirvonen, and J. Hoddinott. 2017. Animal Sourced Foods and Child Stunting. IFPRI Discussion Paper 01695. International Food Policy Research Institute, Washington, DC.

Jang, H., and C. Serra. 2014. Nutrition, epigenetics, and diseases. Clin. Nutr. Res. 3:1-8. https://doi.org/10.7762/cnr.2014.3.1.1.

Johnson, S. B., J. L. Riis, and K. G. Noble. 2016. State of the art review: Poverty and the developing brain. Pediatrics 137:e20153075. https://doi.org/10.1542/peds.2015-3075.

Kennedy, G., T. Ballard, and M. C. Dop. 2013. Guidelines for Measuring Household and Individual Dietary Diversity. FAO, Rome, Italy.

Malcolm, L. A. 1970. Growth retardation in a New Guinea boarding school and its response to supplementary feeding. Br. J. Nutr. 24:297-305. https://doi.org/10.1079/BJN19700029.

Marquis, G. S., J. P. Habicht, C. F. Lanata, R. E. Black, and K. M. Rasmussen. 1997. Breast milk or animal-product foods improve linear growth of Peruvian toddlers consuming marginal diets. Am. J. Clin. Nutr. 66:1102-1109. https://doi.org/10.1093/ajen/66.5 .1102 .

Michaelsen, K. F., A. L. Nielsen, N. Roos, H. Friis, and C. Molgaard. 2011. Cow's milk in treatment of moderate and severe undernutrition in low-income countries. Nestle Nutr. Workshop Ser. Pediatr. Program. 67:99-111. https://doi.org/10.1159/000325578.

Miller, L. C., N. Joshi, M. Lohani, B. Rogers, M. Kershaw, R. Houser, S. Ghosh, J. K. Griffiths, S. Mahato, and P. Webb. 2017. Duration of programme exposure is associated with improved outcomes in nutrition and health: The case for longer project cycles from intervention experience in rural Nepal. J. Dev. Effect. 9:101-119. https: //doi.org/10.1080/19439342.2016.1231706.

Miller, L. C., N. Joshi, M. Lohani, B. L. Rogers, M. Loraditch, R. Houser, P. Singh, and S. Mahato. 2014. Community development and livestock promotion in rural Nepal: Effect on child growth and health. Food Nutr. Bull. 35:312-326. https://doi.org/10.1177/ 156482651403500304

Miller, L. C., S. Neupane, N. Joshi, M. Lohani, B. L. Rogers, S. Neupane, S. Ghosh, and P. Webb. 2020a. Multisectoral community development in Nepal has greater effects on child growth and diet than nutrition education alone. Public Health Nutr. 23:146-161. https://doi.org/10.1017/S136898001900260X.

Miller, L. C., S. Neupane, N. Joshi, M. Shrestha, S. Neupane, M. Lohani, and A. L. Thorne-Lyman. 2020b. Diet quality over time is associated with better development in rural Nepali children. Matern. Child Nutr. 16:e12964. https://doi.org/10.1111/mcn.12964.

Ministry of Health Nepal, New ERA, and ICF. 2017. 2016 Nepal Demographic and Health Survey Key Findings. Ministry of Health Nepal, Kathmandu, Nepal.

Murphy, S. P., C. Gewa, L. J. Liang, M. Grillenberger, N. O. Bwibo, and C. G. Neumann. 2003. School snacks containing animal source foods improve dietary quality for children in rural Kenya. J. Nutr. 133(Suppl. 2):3950S-3956S. https://doi.org/10.1093/jn/133.11 .3950S.

Neumann, C., D. M. Harris, and L. M. Rogers. 2002. Contribution of animal source foods in improving diet quality and function in children in the developing world. Nutr. Res. 22:193-220. https:// doi.org/10.1016/S0271-5317(01)00374-8.

Neumann, C. G., N. O. Bwibo, S. P. Murphy, M. Sigman, S. Whaley, L. H. Allen, D. Guthrie, R. E. Weiss, and M. W. Demment. 2003. Animal source foods improve dietary quality, micronutrient status, growth and cognitive function in Kenyan school children: Background, study design and baseline findings. J. Nutr. 133:3941S3949S. https://doi.org/10.1093/jn/133.11.3941S.
Neumann, C. G., S. P. Murphy, C. Gewa, M. Grillenberger, and N. O. Bwibo. 2007. Meat supplementation improves growth, cognitive, and behavioral outcomes in Kenyan children. J. Nutr. 137:11191123. https://doi.org/10.1093/jn/137.4.1119.

Persson, L. A. 2017. Prenatal nutrition, socioenvironmental conditions, and child development. Lancet Glob. Health 5:e127-e128. https://doi.org/10.1016/S2214-109X(16)30356-4.

Pimpin, L., S. Kranz, E. Liu, M. Shulkin, D. Karageorgou, V. Miller, W. Fawzi, C. Duggan, P. Webb, and D. Mozaffarian. 2019. Effects of animal protein supplementation of mothers, preterm infants, and term infants on growth outcomes in childhood: A systematic review and meta-analysis of randomized trials. Am. J. Clin. Nutr. 110:410-429. https://doi.org/10.1093/ajcn/nqy348.

Prado, E. L., and K. G. Dewey. 2014. Nutrition and brain development in early life. Nutr. Rev. 72:267-284. https://doi.org/10.1111/nure .12102 .

Ruel, M. T. 2003a. Milk intake is associated with better growth in Latin America: Evidence from the demographic and health surveys. FASEB J. 17:A1199.

Ruel, M. T. 2003b. Operationalizing dietary diversity: A review of measurement issues and research priorities. J. Nutr. 133:3911S3926S. https://doi.org/10.1093/jn/133.11.3911S.

Shapiro, M. J., S. M. Downs, H. J. Swartz, M. Parker, D. Quelhas, K. Kreis, K. Kraemer, K. P. West Jr., and J. Fanzo. 2019. A systematic review investigating the relation between animal-source food consumption and stunting in children aged 6-60 months in low and middle-income countries. Adv. Nutr. 10:827-847. https://doi.org/ 10.1093/advances/nmz018.

Smith, J., K. Sones, D. Grace, S. MacMillan, S. Tarawali, and M. Herrero. 2013. Beyond milk, meat, and eggs: Role of livestock in food and nutrition security. Anim. Front. 3:6-13. https://doi.org/ 10.2527/af.2013-0002.

Steyn, N. P., J. Nel, G. Nantel, G. Kennedy, and D. Labadarios. 2006. Food variety and dietary diversity scores in children: Are they good indicators of dietary adequacy? Public Health Nutr. 9:644650. https://doi.org/10.1079/PHN2005912.

Swindale, A., and P. Bilinsky. 2006. Household Dietary Diversity Score (HDDS) for Measurement of Household Food Access: Indicator Guide. Version 2. Food and Nutrition Technical Assistance (FANTA), Washington, DC.

Thorne-Lyman, A., D. Spiegelman, and W. W. Fawzi. 2014. Is the strength of association between indicators of dietary quality and the nutritional status of children being underestimated? Matern. Child Nutr. 10:159-160. https://doi.org/10.1111/mcn.12104.

Thorne-Lyman, A. L., M. Shrestha, W. W. Fawzi, M. Pasqualino, T. A. Strand, I. Kvestad, M. Hysing, N. Joshi, M. Lohani, and L. C. Miller. 2019. Dietary diversity and child development in the far west of Nepal: A cohort study. Nutrients 11:1799. https://doi.org/ $10.3390 /$ nu11081799.

UNICEF. 2018. Malnutrition. Vol. 2018. UNICEF, New York, NY.

Watkins, B. A. 1995. The nutritive value of the egg. Pages 177-194 in Egg Science and Technology. 4th ed. W. J. Stadelman and O. Cotterill, ed. Food Products Press, New York, NY.

Whaley, S. E., M. Sigman, C. Neumann, N. Bwibo, D. Guthrie, R. E. Weiss, S. Alber, and S. P. Murphy. 2003. The impact of dietary intervention on the cognitive development of Kenyan school children. J. Nutr. 133(Suppl. 2):3965S-3971S. https://doi.org/10 $.1093 /$ jn/133.11.3965S.

World Health Organization. 2011. WHO Anthro and Anthro Plus. Version 3.2.2. WHO, Geneva, Switzerland.

\section{ORCIDS}

Laurie C. Miller ํㅏ https://orcid.org/0000-0002-3586-2335 Sumanta Neupane @ https://orcid.org/0000-0003-2977-0896 